\title{
Coronary artery bypass grafting in diabetics: A growing health care cost crisis
}

\author{
Sajjad Raza, MD, ${ }^{\mathrm{a}}$ Joseph F. Sabik III, MD, ${ }^{\mathrm{a}}$ Ponnuthurai Ainkaran, MS, ${ }^{\mathrm{b}}$ and Eugene H. Blackstone, $\mathrm{MD}^{\mathrm{a}, \mathrm{b}}$
}

\section{ABSTRACT}

Objectives: To determine 4-decade temporal trends in the prevalence of diabetes and cardiovascular risk factors among patients undergoing coronary artery bypass grafting $(\mathrm{CABG})$ and to compare in-hospital outcomes, resource utilization, and long-term survival after $\mathrm{CABG}$ in diabetics versus nondiabetics.

Methods: From January 1972 to January 2011, 10,362 pharmacologically treated diabetics and 45,139 nondiabetics underwent first-time CABG. Median follow-up was 12 years. Direct technical cost data were available from 2003 onward $(\mathrm{n}=4679)$. Propensity matching by diabetes status was used for outcome comparisons. Endpoints were in-hospital adverse events, resource utilization, and long-term survival.

Results: Diabetics undergoing CABG increased from $7 \%$ in the 1970 s to $37 \%$ in the 2000s. Their outcomes were worse, with more $(P<.05)$ in-hospital deaths $(2.0 \%$ vs $1.3 \%)$, deep sternal wound infections $(2.3 \%$ vs $1.2 \%)$, strokes $(2.2 \%$ vs $1.4 \%)$, renal failure $(4.0 \%$ vs $1.3 \%)$, and prolonged postoperative hospital stay $(9.6 \%$ vs $6.0 \%)$; and their hospital costs were $9 \%$ greater $(95 \%$ confidence interval 7\%-11\%). Survival after CABG among diabetics versus nondiabetics at $1,5,10$, and 20 years was also worse: $94 \%$ versus $94 \%, 80 \%$ versus $84 \%, 56 \%$ versus $66 \%$, and $20 \%$ versus $32 \%$, respectively. Propensitymatched patients incurred similar costs, but the prevalence of postoperative deep sternal wound infections and stroke, as well as long-term survival, remained worse in diabetics.

Conclusions: Diabetes is both a marker for high-risk, resource-intensive, and expensive care after $\mathrm{CABG}$ and an independent risk factor for reduced long-term survival. These issues, coupled with the increasing proportion of patients needing $\mathrm{CABG}$ who have diabetes, are a growing challenge in reining in health care costs. (J Thorac Cardiovasc Surg 2015;150:304-12)

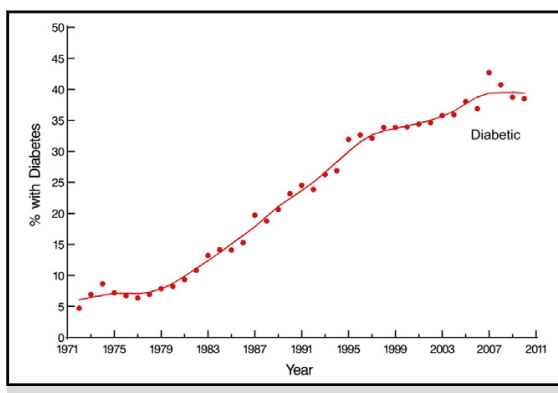

Four-decade trend in prevalence of diabetes among patients undergoing primary isolated coronary artery bypass grafting. Each circle represents a yearly percentage, and the solid line is the locally estimated scatterplot smoother (loess) estimate.

\section{Central Message}

Increasingly, patients needing CABG have diabetes, a marker for high-risk, resource-intensive, expensive care after CABG, and an independent risk factor for reduced long-term survival, creating a growing challenge to health care cost reduction.

\section{Perspective}

The proportion of patients needing CABG who have diabetes has increased to nearly $40 \%$ of all patients undergoing CABG at our institution. The procedure is more resource intensive and expensive for diabetics than for nondiabetics, partly because of postoperative complications. However, when surgeons present the risks and benefits of CABG to diabetic patients, they should explain that CABG offers the best chance for long-term survival.

See Editorial Commentary page 313.

See Editorial page 284.
From the Department of ${ }^{\text {a }}$ Thoracic and Cardiovascular Surgery, Heart and Vascular Institute, Cleveland Clinic; and Department of ${ }^{\mathrm{b}}$ Quantitative Health Sciences, Research Institute, Cleveland Clinic, Cleveland, Ohio.

This study was funded in part by the Sheikh Hamdan bin Rashid Al Maktoum Distinguished Chair in Thoracic and Cardiovascular Surgery (held by JFS), and the Kenneth Gee and Paula Shaw, PhD, Chair in Heart Research (held by EHB). These philanthropists played no role in the design of the study, collection of data, analysis and interpretation of the data, or writing of the report, and did not approve or disapprove publication of the article.

Received for publication Dec 5, 2014; revisions received March 16, 2015; accepted for publication March 29, 2015; available ahead of print May 29, 2015.

Address for reprints: Joseph F. Sabik III, MD, Department of Thoracic and Cardiovascular Surgery, Cleveland Clinic, 9500 Euclid Ave/Desk J4-1, Cleveland, OH 44195 (E-mail: sabikj@ccf.org).

$0022-5223 / \$ 36.00$

Copyright $($ c 2015 by The American Association for Thoracic Surgery

http://dx.doi.org/10.1016/j.jtcvs.2015.03.041
丹 Supplemental material is available online.

Diabetes is an emerging worldwide epidemic that affects 382 million people, ${ }^{1}$ including 25.8 million in the United States alone. ${ }^{2}$ In 2013, global health expenditures resulting from diabetes were estimated at $\$ 548$ billion and are expected to exceed $\$ 627$ billion by 2035 . ${ }^{1}$ In the United States, the total economic burden of diabetes was $\$ 245$ billion in 2012. ${ }^{3}$ Because coronary artery disease is 


\section{Abbreviation and Acronym \\ $\mathrm{CABG}=$ coronary artery bypass grafting}

common in diabetics, ${ }^{4}$ it is an important driver of diabetesrelated health care cost. ${ }^{3}$

As the prevalence of diabetes has risen, cardiovascular disease associated with it has increased as well. ${ }^{5}$ Today, diabetics represent an important subset of patients undergoing coronary artery bypass grafting $(\mathrm{CABG})$, an expensive procedure. Therefore, we sought to determine 4decade temporal trends in the prevalence of diabetes and cardiovascular risk factors for patients undergoing CABG, compare overall in-hospital adverse outcomes, hospital resource utilization and costs, and long-term survival after $\mathrm{CABG}$ in diabetics versus nondiabetics, then compare these same factors in diabetics versus nondiabetics who have similar high-risk profiles using propensity matching.

\section{METHODS \\ Patients}

From January 1, 1972, to January 1, 2011, 57,278 patients underwent first-time isolated CABG at Cleveland Clinic. Data on the presence or absence of pharmacologically treated diabetes mellitus (insulin or oral hypoglycemic agent) were available for 55,501 (97\%) of these patients: 45,139 nondiabetics and 10,362 diabetics.

Patients were identified, and preoperative, operative, and postoperative variables (Appendix E1) were retrieved from the prospective Cleveland Clinic Cardiovascular Information Registry. This database is populated concurrently with patient care and has been approved for use in research by the institutional review board, with the requirement for patient consent waived.

\section{Variables and Definitions}

A coronary artery system was considered meaningfully stenotic if it contained a $\geq 50 \%$-diameter obstruction. Incomplete revascularization was defined as failure to graft any coronary system containing $\geq 50 \%$ stenosis, or both left anterior descending and circumflex coronary systems for $\geq 50 \%$ left main trunk stenosis. Left ventricular function was echocardiographically graded as normal (ejection fraction $\geq 60 \%$ ), mild dysfunction (ejection fraction $40 \%-59 \%$ ), moderate dysfunction (ejection fraction $25 \%-39 \%$ ), or severe dysfunction (ejection fraction $<25 \%$ ).

\section{Endpoints}

Endpoints were: (1) in-hospital adverse outcomes defined as in the Society of Thoracic Surgeons national database (www.ctsnet.org/file/ rptDataSpecifications252_1_ForVendorsPGS.pdf); (2) in-hospital direct technical costs (the sum of direct preoperative, operative, and postoperative costs), both total and broken down according to resource utilization areas; and (3) time-related mortality. Actual direct technical cost data (not charge data), exclusive of physician professional salaries, were obtained from Decision Support Services of Cleveland Clinic. Data were available for patients from only 2003 onward $(n=4679$ : 1776 diabetics and 2903 nondiabetics). Costs were corrected to constant 2011 dollars. ${ }^{6}$ Indirect costs, including institutional costs and capital equipment costs used for all operations, could not be estimated on a per patient basis and are not included, but they were assumed to be distributed uniformly across groups.

Vital status after hospital discharge was obtained by routine anniversary follow-up questionnaires supplemented with data from the Social Security Death Master File, ${ }^{7}$ accessed on October 27, 2011, with a closing date of
April 27, 2011. A total of 714,709 patient-years of follow-up data were available for analyses. Median follow-up was 11.8 years, with $25 \%$ of survivors followed for $>21$ years, and $10 \%$ for $>30$ years.

For diabetic patients, 86,153 patient-years of follow-up data were available for analyses, with a median follow-up period of 7.5 years; $25 \%$ of survivors were followed for $>12$ years, and $10 \%$ for $>18$ years. For nondiabetic patients, 628,556 patient-years of follow-up data were available for analyses, with a median follow-up period of 13 years; $25 \%$ of survivors were followed for $>24$ years, and $10 \%$ for $>31$ years.

\section{Statistical Analysis}

Temporal trends. Four-decade temporal trends in the prevalence of diabetes and cardiovascular risk factors among patients undergoing CABG were assessed using plots of yearly percentages or averages over time. A nonparametric locally estimated scatterplot smoother, PROC LOESS (SAS Institute, Cary, NC), was used to smooth these temporal trends.

In-hospital adverse outcomes. Comparisons of outcomes after CABG between diabetics and nondiabetics, unmatched and propensity matched, were made using the $\chi^{2}$ test for categoric endpoints.

Resource utilization and total direct technical cost. Hours in the intensive care unit and postoperative and total hospital lengths of stay had right-skewed distributions, so the Wilcoxon rank-sum test, and the median score test for continuous endpoints, were used for comparisons between diabetics and nondiabetics. To identify the relative difference in direct technical costs, we estimated the ratio of the median cost between the 2 groups. The percentile bootstrap confidence method ${ }^{8}$ was used to estimate $95 \%$ confidence intervals. This procedure was applied to the overall and matched cohorts.

Long-term survival. Survival was assessed nonparametrically, using the Kaplan-Meier method, and parametrically, using a multiphase hazard model. ${ }^{9}$ The latter involved resolving the number of hazard phases for instantaneous risk of death (hazard function), and estimating shaping parameters. (For details, see www.lerner.ccf.org/qhs/software/hazard.) Because the shape of time-varying risk of death may differ for diabetics versus nondiabetics, we constructed separate hazard models for each group.

Propensity-score matching. Although overall assessment of outcomes in diabetics compared with nondiabetics represents the realities of the real world, diabetics as a group present with a higher-than-average risk profile. We therefore treated diabetes as a "natural experiment," 10 comparing outcomes of propensity-matched diabetics and nondiabetics. $^{11-13}$ This comparison was accomplished in 2 steps. First, a parsimonious multivariable logistic regression was used to identify differences in preoperative characteristics of diabetic versus nondiabetic patients, to obtain insight into these differences (see Appendix E1 for a list of variables analyzed). Bootstrap bagging for variable selection with automated analysis of 500 resampled datasets was used to accomplish this, followed by tabulation of the frequency of both single factors and closely related clusters of factors. ${ }^{14}$ We retained factors that occurred in $\geq 50 \%$ of the bootstrap models (Table E1). The C-statistic for this parsimonious model was .83 .

Second, the parsimonious model was augmented into a saturated propensity model by including patient characteristics that were not statistically significantly different between groups. These characteristics were demographic, cardiac, and noncardiac comorbidities not represented (see Appendix E1). The C-statistic for this model was .84.

A propensity score representing the probability of diabetes-group membership given the variables included in the propensity model, regardless of whether the patient had diabetes-was then calculated for each patient. A greedy matching strategy based on the propensity scores alone was used to match diabetic with nondiabetic patients, yielding 8926 well-matched pairs ( $86 \%$ of possible matches; Figure E1). Diabetes 
cases with propensity scores that deviated $>0.10$ from those of nondiabetes cases were considered unmatched. Standardized differences demonstrated that covariable balance was achieved across nearly all variables (Figure E2).

Using a similar approach, separate propensity matching was done between the subset of diabetics and nondiabetics undergoing an operation in the period from 2003 to 2011, during which cost data were available. This yielded 1368 well-matched pairs (77\% of possible matches).

Missing values. Several variables examined in multivariable analyses had missing values. We used fivefold multiple imputation ${ }^{15}$ with a Markov chain Monte Carlo technique to impute missing values (SAS PROC MI; SAS Institute, Cary, NC). In multivariable modeling, for each imputed complete dataset, we estimated regression coefficients and their variance-covariance matrix. After this step, following Rubin, ${ }^{15}$ we combined estimates from the 5 models (SAS PROC MIANALYZE; SAS Institute, Cary, NC) to yield final regression coefficient estimates, the variance-covariance matrix, and $P$ values.

Presentation. Continuous variables are summarized by mean \pm SD, or equivalent 15th, 50th (median), and 85th percentiles when the distribution of values is skewed. Analyses were performed using SAS statistical software, version 9.1 (SAS Institute, Cary, NC) and R (version 3.0.2). Uncertainty is expressed by confidence limits (CLs) equivalent to \pm 1 SE $(68 \%)$.

\section{RESULTS}

Compared with nondiabetics, diabetic patients undergoing CABG were older and more likely to be overweight, and more likely to be women. In addition, they were more likely to have a history of heart failure, peripheral arterial disease, carotid disease, hypertension, renal failure, stroke, and advanced coronary artery disease (Table 1).

\section{Temporal Trends}

The proportion of patients presenting for CABG who have diabetes increased from $7 \%$ per year in the 1970 s to $37 \%$ in the 2000s (Central Image). The cardiovascular risk factor profile also changed during this time, more so for diabetics than nondiabetics. Today, patients are likely to be older (Figure 1,A) and obese (Figure 1, B); to have had a stroke (Figure 1,C); and to have hypertension (Figure 1,D), peripheral arterial disease (Figure 1,E), lower total cholesterol (Figure 1, F), higher high-density lipoprotein cholesterol (Figure 1, G), lower triglycerides (Figure 1, $H$ ), and more-advanced coronary artery disease (Figure 1, I) (see Table E1).

\section{Overall Outcomes}

In-hospital adverse outcomes, and resource utilization and direct technical costs. Diabetics had higher inhospital mortality and greater occurrence of deep sternal wound infection, stroke, atrial fibrillation, renal failure, and respiratory failure (Table 2). Hours spent in the intensive care unit and of length of stay $>14$ days were higher in diabetics than nondiabetics (Table 2). As a result, the total cost of CABG was $9 \%$ greater $(95 \%$ CI, $7 \%-11 \%$ ) in diabetics. Most of this difference was due to higher costs of clinical and laboratory testing, diagnostic imaging, pharmacy services, and nursing care (Figure 2).

Long-term survival. The instantaneous risk of death was high immediately after CABG, decreased over the ensuing 6 months, and then gradually increased for both diabetics and nondiabetics (Figure 3, A), resulting in early divergence of their survival curves (Figure 3,B). In addition, late hazard was elevated in diabetics; thus, ever-increasing divergence of survival was observed out to at least 20 years. Among diabetics, overall survival at 6 months, 1, 5, 10, 15, and 20 years after CABG was $95 \%, 94 \%, 80 \%, 54 \%$, $31 \%$, and $18 \%$, respectively. In contrast, for nondiabetics, it was $97 \%, 97 \%, 90 \%, 76 \%, 59 \%$, and $42 \%$, respectively $(P<.0001)$.

\section{Comparison of Diabetics with Similar High-Risk Nondiabetics}

In-hospital adverse outcomes, and resource utilization and direct technical costs. After matching, the incidence of deep sternal wound infection and stroke remained significantly higher among diabetics (Table 2). After propensity matching, no significant difference remained in total cost of CABG between diabetics and nondiabetics (Figure 2). Hours spent in the intensive care unit were similar, but length of stay $>14$ days remained higher for diabetics (Table 2).

Long-term survival. Among propensity-matched patients, instantaneous risk of death (hazard function) was similar for both diabetics and nondiabetics until 1 year after surgery, after which risk of death was greater for diabetics (Figure 3,C). Early survival was similar between the 2 groups, but late survival was worse for diabetics (Figure 3,D). Late survival continued to diverge as long as patients were followed, because of the substantial difference in late hazard for at least 20 years after CABG. Survival of diabetics at 6 months, $1,5,10,15$, and 20 years after operation was $96 \%, 94 \%, 80 \%, 56 \%, 35 \%$, and $20 \%$, respectively, versus $96 \%, 94 \%, 84 \%, 66 \%, 47 \%$, and $32 \%$ for nondiabetics.

\section{DISCUSSION \\ Principal Findings}

This study shows that the proportion of patients presenting for CABG who have diabetes increased each year during the past 4 decades, as did the proportion with cardiovascular risk factors. Thus, compared with diabetics undergoing operation in the 1970s, 1980s, and 1990s, those operated on more recently were more likely to be obese and have more comorbidities and advanced coronary artery disease. For diabetics, CABG was more resource intensive and expensive, and in-hospital adverse events and long-term survival were worse. However, the increase in in-hospital resource utilization was not specific to diabetics, but rather commensurate with that of patients coming to surgery with 
TABLE 1. Patient characteristics and revascularization details of nondiabetics and diabetics undergoing coronary artery bypass grafting

\begin{tabular}{|c|c|c|c|c|c|}
\hline \multirow[b]{2}{*}{ Characteristic } & \multicolumn{2}{|c|}{ Nondiabetics $(n=45,139)$} & \multicolumn{2}{|c|}{ Diabetics $(n=10,362)$} & \multirow[b]{2}{*}{$P$ value } \\
\hline & $\mathbf{n}$ & No. $(\%)$ or mean \pm SD & $\mathbf{n}$ & No. $(\%)$ or mean \pm SD & \\
\hline \multicolumn{6}{|l|}{ Demographics } \\
\hline Age (y) & 45,139 & $60 \pm 10$ & 10,362 & $63 \pm 9.7$ & $<.001$ \\
\hline Male & 45,139 & $37,626(83)$ & 10,362 & $7249(70)$ & $<.001$ \\
\hline Body mass index $\left(\mathrm{kg} / \mathrm{m}^{2}\right)$ & 27,739 & $28 \pm 4.7$ & 8883 & $30 \pm 5.8$ & $<.001$ \\
\hline \multicolumn{6}{|l|}{ Symptoms and surgical priorities } \\
\hline NYHA functional class & 44,775 & & 10,317 & & $<.001$ \\
\hline I & & 7645 (17) & & $1800(17)$ & \\
\hline II & & $16,533(37)$ & & $3982(39)$ & \\
\hline III & & $4702(11)$ & & $1468(14)$ & \\
\hline IV & & $15,895(35)$ & & $3067(30)$ & \\
\hline Emergency operation & 45,137 & $1242(2.8)$ & 10,362 & $248(2.4)$ & .04 \\
\hline \multicolumn{6}{|l|}{ Cardiac comorbidity } \\
\hline Myocardial infarction & 45,139 & $22,916(51)$ & 10,362 & $5932(57)$ & $<.001$ \\
\hline Left ventricular dysfunction & 42,404 & & 8996 & & $<.001$ \\
\hline None & & $37,013(87)$ & & $6300(70)$ & \\
\hline Mild & & $2492(5.9)$ & & $948(11)$ & \\
\hline Mild to moderate & & $514(1.2)$ & & $238(2.6)$ & \\
\hline Moderate & & $1315(3.1)$ & & $688(7.6)$ & \\
\hline Moderate to severe & & $492(1.2)$ & & $384(4.3)$ & \\
\hline Severe & & $578(1.4)$ & & $438(4.9)$ & \\
\hline Preoperative AF or flutter & 36,357 & $411(1.1)$ & 8967 & $163(1.8)$ & $<.001$ \\
\hline Heart failure & 45,139 & $2219(4.9)$ & 10,362 & $1750(17)$ & $<.001$ \\
\hline Coronary artery disease & 35,015 & $20,687(59)$ & 7042 & $3446(49)$ & $<.001$ \\
\hline No. of coronary systems diseased (stenosis $\geq 50 \%$ ) & 43,113 & & 9908 & & $<.001$ \\
\hline 0 & & $366(0.85)$ & & $69(0.70)$ & \\
\hline 1 & & $5310(12)$ & & $615(6.2)$ & \\
\hline 2 & & $13,807(32)$ & & $2332(24)$ & \\
\hline 3 & & $23,630(55)$ & & $6892(70)$ & \\
\hline Left main disease (stenosis $\geq 50 \%$ ) & 41,909 & $6704(16)$ & 9277 & $1749(19)$ & $<.001$ \\
\hline \multicolumn{6}{|l|}{ Noncardiac comorbidity } \\
\hline Peripheral arterial disease & 45,139 & $4551(10)$ & 10,362 & $1840(18)$ & $<.001$ \\
\hline Carotid disease & 45,139 & $3434(7.6)$ & 10,362 & $2278(22)$ & $<.001$ \\
\hline Stroke & 45,139 & $1515(3.4)$ & 10,362 & $880(8.5)$ & $<.001$ \\
\hline Hypertension & 29,346 & $17,615(60)$ & 9077 & $6966(77)$ & $<.001$ \\
\hline COPD & 14,360 & $1079(7.5)$ & 6639 & $584(8.8)$ & $<.001$ \\
\hline Smoking & 44,244 & $24,133(55)$ & 10,208 & $5319(52)$ & $<.001$ \\
\hline Creatinine (mg/dL) & 13,969 & $1.2 \pm 0.83$ & 6464 & $1.3 \pm 1.2$ & .07 \\
\hline Blood urea nitrogen $(\mathrm{mg} / \mathrm{dL})$ & 13,954 & $18 \pm 9.0$ & 6460 & $22 \pm 12$ & $<.001$ \\
\hline Renal dialysis & 7375 & $59(0.80)$ & 4060 & $98(2.4)$ & $<.001$ \\
\hline Total cholesterol (mg/dL) & 35,236 & $235 \pm 56$ & 7422 & $208 \pm 60$ & $<.001$ \\
\hline HDL cholesterol (mg/dL) & 14,734 & $40 \pm 12$ & 5283 & $39 \pm 13$ & $<.001$ \\
\hline LDL cholesterol (mg/dL) & 9616 & $128 \pm 46$ & 4309 & $113 \pm 45$ & $<.001$ \\
\hline Triglycerides (mg/dL) & 29,248 & $185 \pm 116$ & 6672 & $203 \pm 173$ & .002 \\
\hline Bilirubin (mg/dL) & 12,683 & $0.65 \pm 0.50$ & 5803 & $0.59 \pm 0.51$ & $<.001$ \\
\hline Hematocrit $(\%)$ & 13,037 & $40 \pm 5.1$ & 5993 & $38 \pm 5.5$ & $<.001$ \\
\hline \multicolumn{6}{|l|}{ Experience } \\
\hline January 1,1972 to index operation & 45,139 & $14 \pm 9.5$ & 10,362 & $21 \pm 9.6$ & $<.001$ \\
\hline \multicolumn{6}{|l|}{ Revascularization details } \\
\hline ITA grafts at index operation & 45,139 & & 10,362 & & $<.001$ \\
\hline None & & $14,888(33)$ & & 2018 (19) & \\
\hline Single & & $25,160(56)$ & & $7570(73)$ & \\
\hline Bilateral & & $5091(11)$ & & $774(7.5)$ & \\
\hline Complete revascularization* & 45,139 & $40,405(90)$ & 10,362 & $9432(91)$ & $<.001$ \\
\hline Cardiopulmonary bypass & 45,139 & 43,761 (97) & 10,362 & $9817(95)$ & $<.001$ \\
\hline
\end{tabular}

Values in " $\mathrm{n}$ " columns are numbers of patients with data available. $S D$, Standard deviation; $N Y H A$, New York Heart Association; $A F$, atrial fibrillation; $C O P D$, chronic obstructive pulmonary disease; $H D L$, high-density lipoprotein; $L D L$, low-density lipoprotein; ITA, internal thoracic artery. *Incomplete revascularization was defined as failure to graft any system containing $50 \%$ stenosis or both the left anterior descending and circumflex coronary artery systems for $50 \%$ left main trunk stenosis. 


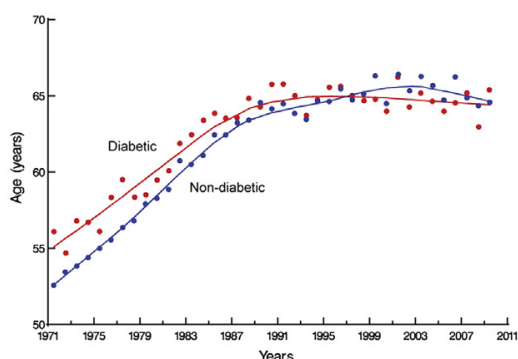

A
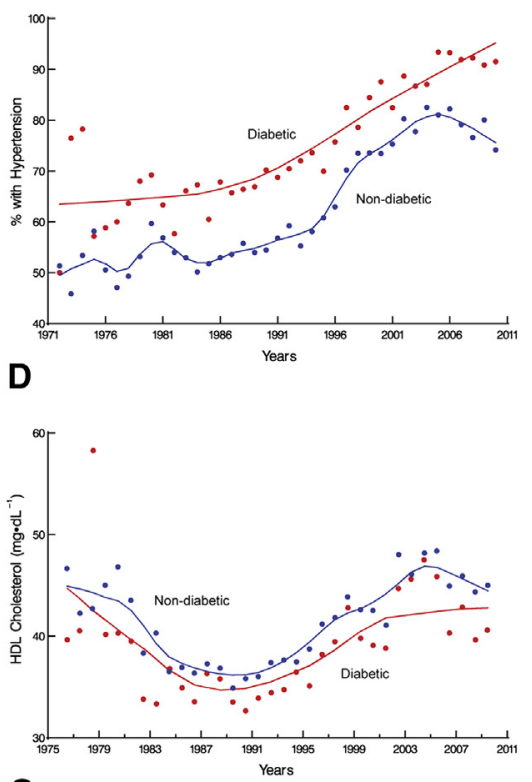

G

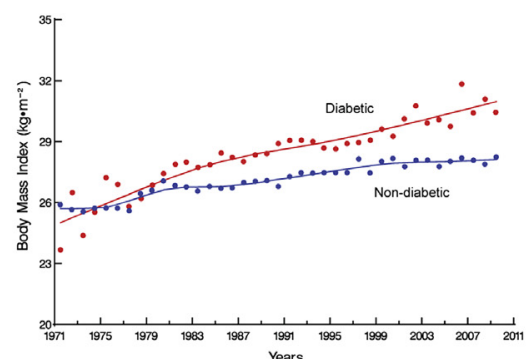

B
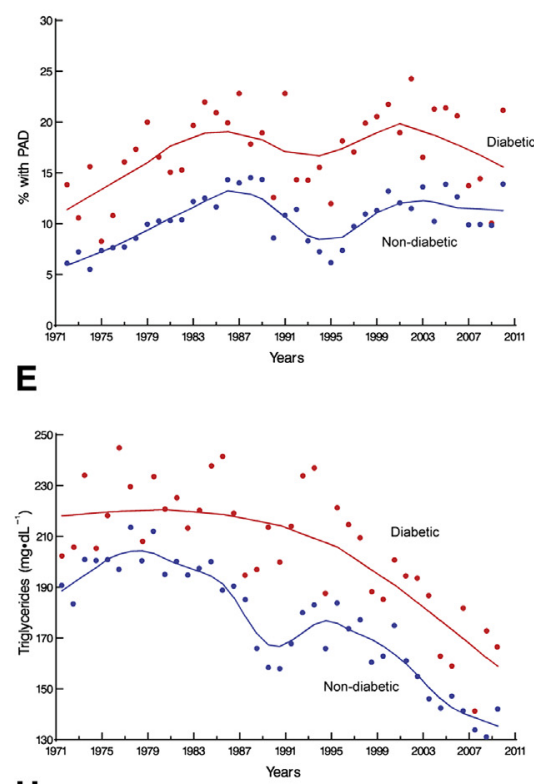

H

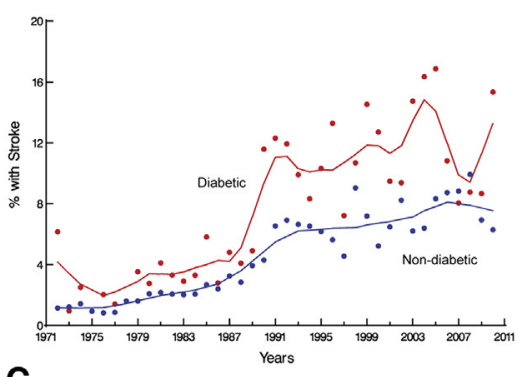

C
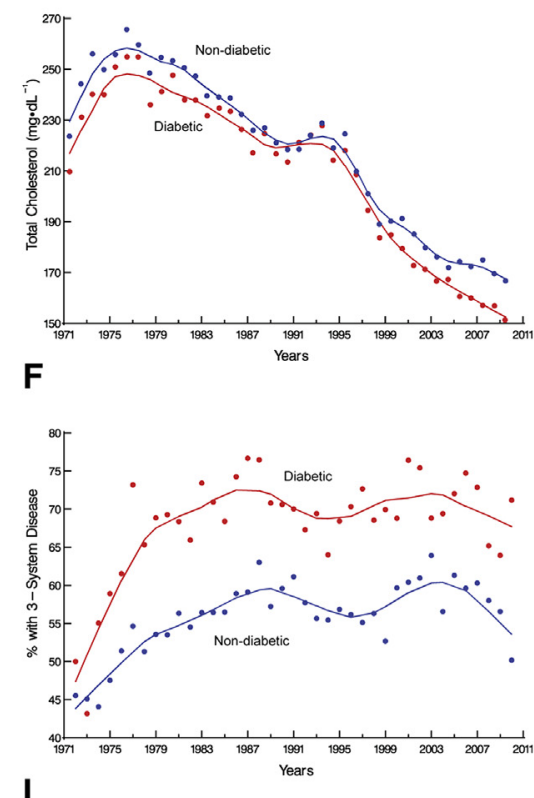

FIGURE 1. Four-decade trends in prevalence of diabetes and cardiovascular risk factors among patients undergoing primary isolated coronary artery bypass grafting. Each circle is a yearly percentage or mean value, and solid lines are loess estimates. The factors shown are: (A) age; (B) body mass index; (C) stroke; (D) hypertension; (E) PAD; (F) total cholesterol; (G) HDL cholesterol; (H) triglycerides; and (I) percentage with 3-system disease. $P A D$, Peripheral arterial disease; $H D L$, high-density lipoprotein.

a similar extent of comorbidities, but without diabetes. Unadjusted in-hospital and early mortality (1-year) were higher in diabetics than in nondiabetics, but similar for propensity-matched patients with a similar comorbidity profile. Long-term survival was worse in diabetics than in either nondiabetic patients or matched, nondiabetic, highrisk patients. Thus, diabetes is both a marker for highrisk, resource-intensive, and expensive care after CABG, and an independent risk factor for reduced long-term survival.

\section{Trends}

In 2010 , nearly $40 \%$ of those undergoing CABG at our institution were diabetic, paralleling the rising prevalence of diabetes in the general population. However, the increasing use of percutaneous coronary intervention for revascularization, and the choice of $\mathrm{CABG}$ as the preferred revascularization strategy for diabetics, could also have been contributing factors. ${ }^{16}$ Although cardiovascular disease-related morbidity and mortality has clearly been reduced in the United States over the past 50 years, the cardiovascular disease burden attributable to diabetes has increased. ${ }^{5}$ Current estimates are that 18.8 million people in the United States have been diagnosed with diabetes, and 7 million remain undiagnosed. ${ }^{2}$ In addition, nearly 79 million people aged $\geq 20$ years have prediabetes, ${ }^{2}$ a condition that places them at increased risk of developing diabetes and cardiovascular disease. ${ }^{17}$

We also observed a change in the cardiovascular riskfactor profile over time. Diabetics undergoing CABG in recent years are more likely to be obese and to have moreadvanced coronary artery disease than those operated on in the 1970s, 1980s, and 1990s. In addition, they are more likely to have hypertension, one component of metabolic syndrome, together with diabetes, hyperlipidemia, and obesity—all risk factors for coronary artery disease. ${ }^{18}$ Obesity is now considered a national epidemic and is of particular importance as a well-recognized contributor to 
TABLE 2. In-hospital outcomes after coronary artery bypass grafting: overall and propensity matched

\begin{tabular}{|c|c|c|c|c|c|c|c|c|c|c|}
\hline \multirow[b]{3}{*}{ Outcome } & \multicolumn{5}{|c|}{ Overall } & \multicolumn{5}{|c|}{ Propensity matched } \\
\hline & \multicolumn{2}{|c|}{$\begin{array}{c}\text { Nondiabetic } \\
\text { (total } n=45,139)\end{array}$} & \multicolumn{2}{|c|}{$\begin{array}{c}\text { Diabetic } \\
\text { (total } \mathbf{n}=\mathbf{1 0 , 3 6 2 )}\end{array}$} & \multirow[b]{2}{*}{$P$ value } & \multicolumn{2}{|c|}{$\begin{array}{c}\text { Nondiabetic } \\
\text { (total } \mathbf{n}=8926)\end{array}$} & \multicolumn{2}{|c|}{$\begin{array}{c}\text { Diabetic } \\
\text { (total } \mathbf{n}=\mathbf{8 9 2 6})\end{array}$} & \multirow[b]{2}{*}{$P$ valu } \\
\hline & $\mathbf{n}$ & No. $(\%)$ & $\mathbf{n}$ & No. $(\%)$ & & $\mathbf{n}$ & No. $(\%)$ & $\mathbf{n}$ & No. $(\%)$ & \\
\hline Hospital death & 45,139 & $566(1.3)$ & 10,362 & $211(2.0)$ & $<.001$ & 8926 & $152(1.7)$ & 8926 & $174(1.9)$ & .2 \\
\hline Deep sternal wound infection & 45,139 & $526(1.2)$ & 10,362 & $239(2.3)$ & $<.001$ & 8926 & $116(1.3)$ & 8926 & $197(2.2)$ & $<.001$ \\
\hline Septicemia & 14,298 & $226(1.6)$ & 6633 & $151(2.3)$ & .004 & 6393 & $139(2.2)$ & 5352 & $113(2.1)$ & .8 \\
\hline Stroke & 45,139 & $640(1.4)$ & 10,362 & $233(2.2)$ & $<.001$ & 8926 & $134(1.5)$ & 8926 & $200(2.2)$ & $<.001$ \\
\hline Perioperative MI & 45,139 & $1023(2.3)$ & 10,362 & $135(1.3)$ & $<.001$ & 8926 & $118(1.3)$ & 8926 & $123(1.4)$ & .8 \\
\hline Bleeding or tamponade & 45,139 & $1791(4.0)$ & 10,362 & $348(3.4)$ & .004 & 8926 & $271(3.0)$ & 8926 & $314(3.5)$ & .07 \\
\hline Atrial fibrillation & 45,139 & $5148(12)$ & 10,362 & $1979(19)$ & $<.001$ & 8926 & $1914(21)$ & 8926 & $1672(19)$ & $<.001$ \\
\hline Renal failure & 45,139 & $569(1.3)$ & 10,362 & $418(4.0)$ & $<.001$ & 8926 & $258(2.9)$ & 8926 & $285(3.2)$ & .2 \\
\hline Renal failure requiring dialysis & 14,298 & $104(0.73)$ & 6633 & $86(1.3)$ & $<.001$ & 6393 & $79(1.2)$ & 5352 & $60(1.1)$ & .6 \\
\hline Prolonged ventilation $(>24 \mathrm{~h})$ & 3492 & $320(9.2)$ & 2100 & $249(12)$ & .001 & 1838 & $212(12)$ & 1563 & $160(10)$ & .2 \\
\hline \multicolumn{11}{|l|}{ Length of stay* } \\
\hline ICU (h) & 14,296 & $24 / 24 / 72$ & 631 & $24 / 26 / 95$ & $<.001$ & 6391 & $24 / 24 / 75$ & 5351 & $24 / 24 / 76$ & $<.001$ \\
\hline Postoperative (d) & 44,014 & $6.1 / 8.0 / 11$ & 10,263 & $5.9 / 7.9 / 12$ & $<.001$ & 8864 & $5.2 / 7.0 / 11$ & 8829 & $5.9 / 7.9 / 11$ & $<.001$ \\
\hline Hospital (d) & 44,014 & 7/11/17 & 10,263 & $6.3 / 10 / 18$ & $<.001$ & 8864 & $6.3 / 9.3 / 16$ & 8829 & $6.3 / 10 / 17$ & $<.001$ \\
\hline Prolonged $(>14 \mathrm{~d})$ & 45,139 & $2688(6.0)$ & 10,362 & 995 (9.6) & $<.001$ & 8926 & $679(7.6)$ & 8926 & $785(8.8)$ & .004 \\
\hline
\end{tabular}

Values in "n" columns are numbers of patients with data available. $P$ values are given for the median score test. $M I$, Myocardial infarction; $I C U$, intensive care unit. * 15 th/50th/ 85 th percentiles. Median score test was used to compare medians and Wilcoxon rank-sum test to compare tails of distributions.

diabetes. More than one third of US adults are obese, ${ }^{19}$ and in the next 20 years, obesity may play a contributing role in an estimated 6 million cases of diabetes. ${ }^{20}$ On the other hand, diabetics undergoing CABG in recent years had lower total cholesterol, higher high-density lipoprotein cholesterol, and lower triglycerides than did patients operated on in earlier years; this difference may be attributable to better control of lipids in the statin era.

\section{In-Hospital Adverse Outcomes}

In-hospital adverse outcomes after CABG were more common in diabetics than nondiabetics. In part, this difference is attributable to diabetic patients being sicker and having more comorbidities than nondiabetics, because some of the differences, including hospital death, septicemia, renal failure, and respiratory failure, became statistically insignificant after comparison with similar high-risk nondiabetic patients through propensity matching. However, occurrence of deep sternal wound infection and stroke remained significantly higher in diabetics even after matching. Deep sternal wound infection results in prolonged postoperative length of stay and thus increases hospital resource utilization. Strokes may cause permanent disability, resulting in unemployment and thus increasing the indirect cost of diabetes through loss of productivity.
OVERALL

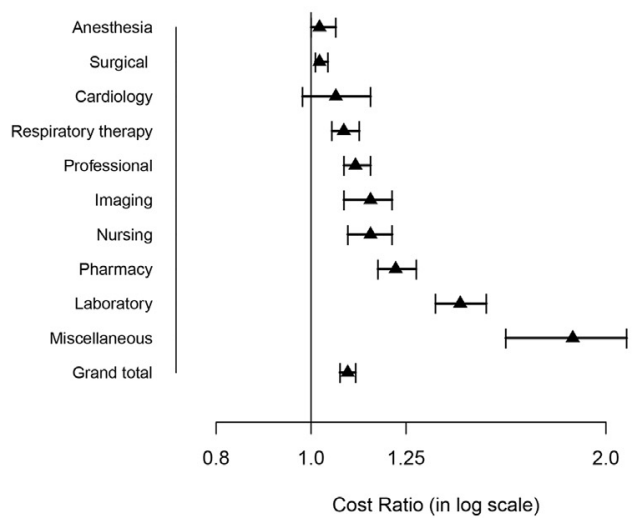

MATCHED

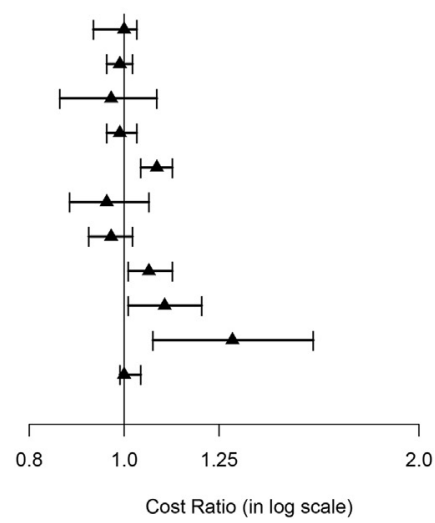

FIGURE 2. Median (triangles) ratio of total direct technical costs (overall and propensity matched) in diabetics versus nondiabetics. Error bars are $95 \%$ confidence intervals. 


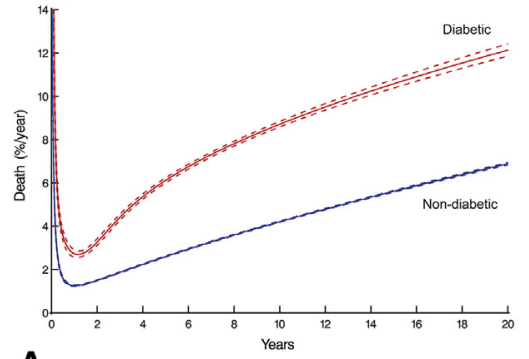

A

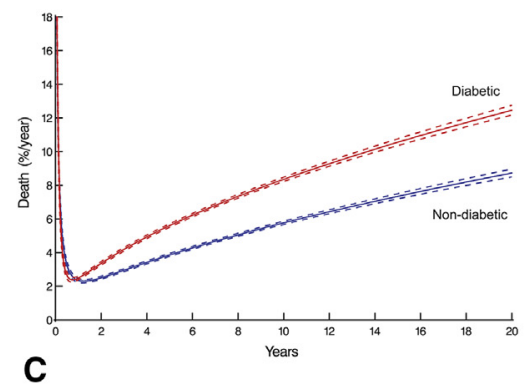

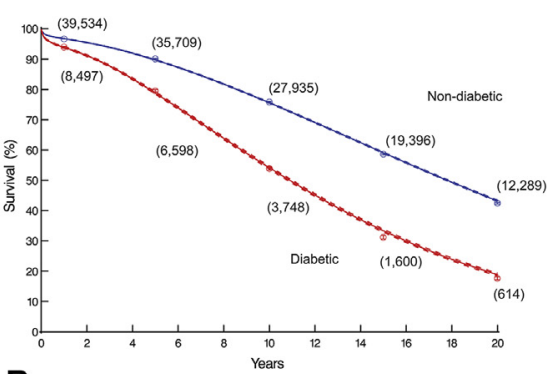

B

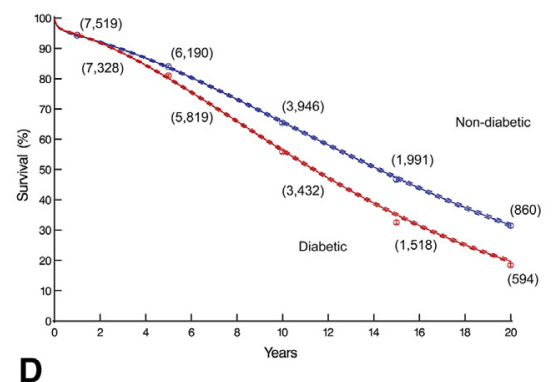

FIGURE 3. Time-related death after primary isolated coronary artery bypass grafting in diabetics and nondiabetics. Solid lines are parametric estimates enclosed within dashed $68 \%$ confidence bands equivalent to \pm 1 SE. The panels show: (A) instantaneous risk of death (overall); (B) survival (overall); (C) instantaneous risk of death (propensity-matched cohort); and (D) survival (propensity-matched cohort). Each symbol represents a death; vertical bars are confidence limits equivalent to $\pm 1 \mathrm{SE}$; and values in parentheses are numbers of patients remaining at risk.

Other studies have also revealed worse hospital and longterm outcomes of CABG in diabetics. ${ }^{21,22}$ The SYNTAX trial showed that at 3 years, diabetes had little effect on outcomes of CABG, and diabetes control (as indicated by baseline hemoglobin A1c levels) was not predictive of major adverse cardiac and cerebrovascular events. In our study, overall postoperative prevalence of stroke and inhospital death was higher in diabetics, and occurrence of myocardial infarction was higher in nondiabetics. However, after comparison with similar, high-risk, nondiabetic patients, occurrence of death and myocardial infarction was similar in the 2 groups, as was true in the SYNTAX trial, but stroke remained higher in diabetics. ${ }^{23}$

\section{Health Care Costs}

Our study additionally shows that resource utilization and the actual direct technical cost of CABG were greater in diabetics, mainly because of longer intensive care unit and postoperative stays, and higher costs of clinical and laboratory testing, diagnostic imaging, pharmacy services, and nursing care. Greater severity of disease among diabetics necessitates preoperative admission and moreextensive laboratory and diagnostic workup. Furthermore, managing postoperative adverse events and the resulting increase in postoperative length of stay both lead to higher in-hospital costs.

After using propensity matching to compare similar high-risk, nondiabetic patients, no significant difference between the total cost of CABG in diabetics versus nondiabetics with a similar high-risk profile was observed, demonstrating that most of the increased cost was due to diabetics being sicker and having more comorbidities. In 2012, \$176 billion was spent on direct health care for diabetics in the United States, with in-hospital care representing $43 \%$ of that amount. ${ }^{3}$ Because heart disease is one of the leading causes of hospitalization in diabetics, a large share of in-hospital costs can be attributed to $\mathrm{CABG}$ and its postoperative complications.

Others have also demonstrated the association of diabetes with increased cost of CABG. ${ }^{24,25}$ A study of 114 diabetics and 198 nondiabetics showed that insulin-treated diabetics have longer hospital stays and higher hospital charges than non-insulin-treated diabetics and nondiabetics. ${ }^{24} \mathrm{~A}$ recently published study from China also showed that CABG was more costly, with worse long-term results, in diabetics than in nondiabetics. ${ }^{26}$

\section{Survival}

Diabetic patients as a group had a higher early (1-year) risk of death after CABG than nondiabetics, as has been documented by others. ${ }^{21}$ However, an interesting finding of our study is that among propensity-matched patients, early risk was similar to that of nondiabetic high-risk patients with a similar comorbidity profile. Long-term survival, however, was worse in diabetics than in both nondiabetic patients and nondiabetic high-risk patients. Other studies have also demonstrated diabetes to be an independent risk factor for reduced long-term survival after 
CABG. ${ }^{21,26}$ Although long-term survival after CABG is worse in diabetics and high-risk nondiabetics, in general, high-risk patients reap the greatest survival benefit from CABG. ${ }^{27}$ Moreover, using surgical techniques that are associated with better long-term survival after CABG in diabetics could further enhance this survival benefit. ${ }^{28}$

\section{Diabetes: An Avoidable Economic Burden}

Diabetes is a growing threat to the US economy. Diabetic patients' medical expenses are nearly 2.3 times higher than those of nondiabetics, ${ }^{3}$ and this economic burden is expected to increase as the number of diabetes cases rises. Fortunately, however, this situation is largely preventable. In people with prediabetes, cost-effective lifestyle interventions have been shown to have a positive effect on preventing development of the disease. ${ }^{29-31}$ In people with diagnosed diabetes, controlling blood sugar and cardiovascular disease risk factors, such as hypertension and hypercholesterolemia, has been shown to help reduce cardiovascular events. ${ }^{32,33}$ With appropriate use of these approaches, we can help prevent development of diabetes and its complications, reducing the diabetes-related economic burden.

\section{Strengths and Limitations}

This study includes 4 decades of patients who underwent CABG at a single, high-volume academic medical center. An advantage of a long observation period is having a long follow-up period, but generalizing these late results to a contemporary patient population may not accurately reflect the changing patient case mix and advances in managing these patients over time. For adjusted comparison of outcomes, propensity-score matching was performed. Although the patient pairs were well matched, any patient factors that significantly affect outcomes after CABG but were not included in the propensity analysis might bias our adjusted results. In addition, circumstances of each death, which may differ among diabetic and nondiabetic patients, were not reliably captured during follow-up inquiries.

\section{CONCLUSIONS}

Diabetes is both a marker for high-risk, resourceintensive, and expensive care after CABG and an independent risk factor for reduced long-term survival. These issues, coupled with the annually increasing number of patients needing CABG who are diabetic, present a growing challenge to reining in health care costs, both in the United States and internationally. Diabetic patients, and those with a similar high-risk profile, set to undergo CABG should be made aware that their risks of postoperative complications are higher than average, and measures should be taken to reduce their postoperative complications. Moreover, trying to reverse the diabetes epidemic is important; if left uncontrolled, it will increase the prevalence of cardiovascular disease and add to the ever-increasing economic health care burden. Research and policies focused on reducing diabetes, and programs that raise awareness about preventive strategies, should be developed and implemented to check rising health care costs.

\section{Conflict of Interest Statement}

Dr Sabik is the North American principal investigator for the Abbott Laboratories-sponsored left main coronary disease randomized trial (EXCEL), is on the Society of Thoracic Surgeons Board of Directors, and is on the scientific advisory board of Medtronic. All other authors have nothing to disclose with regard to commercial support.

\section{References}

1. International Diabetes Federation. IDF diabetes atlas. 6th ed. Available at: http:// www.idf.org/diabetesatlas.

2. Centers for Disease Control and Prevention. National diabetes fact sheet: national estimates and general information on diabetes and prediabetes in the United States. Atlanta: US Department of Health and Human Services; 2011.

3. Economic costs of diabetes in the U.S. in 2012. Diabetes Care. 2013;36:1033-46.

4. Beckman JA, Creager MA, Libby P. Diabetes and atherosclerosis: epidemiology, pathophysiology, and management. JAMA. 2002;287:2570-81.

5. Fox CS, Coady S, Sorlie PD, D’Agostino RB Sr, Pencina MJ, Vasan RS, et al. Increasing cardiovascular disease burden due to diabetes mellitus: the Framing ham Heart Study. Circulation. 2007;115:1544-50.

6. US Department of Labor, Bureau of Labor Statistics. CPI inflation calculator. Available at: http://www.bls.gov/data/inflation_calculator.htm.

7. Boyle CA, Decoufle P. National sources of vital status information: extent of coverage and possible selectivity in reporting. Am J Epidemiol. 1990;131:160-8.

8. Efron B, Tibshirani RJ. An Introduction to the Bootstrap. New York: Chapman and Hall/CRC; 1998.

9. Blackstone EH, Naftel DC, Turner ME Jr. The decomposition of time-varying hazard into phases, each incorporating a separate stream of concomitant information. J Am Stat Assoc. 1986;81:615-24.

10. Pattakos G, Koch CG, Brizzio ME, Batizy LH, Sabik JF III, Blackstone EH, et al Outcome of patients who refuse transfusion after cardiac surgery: a natural experiment with severe blood conservation. Arch Intern Med. 2012;172:1154-60.

11. Rosenbaum PR, Rubin DB. The central role of the propensity score in observational studies for causal effects. Biometrika. 1983;70:41-55.

12. Rubin DB. The design versus the analysis of observational studies for causal effects: parallels with the design of randomized trials. Stat Med. 2007;26:20-36.

13. Sauerbrei W, Schumacher M. A bootstrap resampling procedure for model building: application to the Cox regression model. Stat Med. 1992;11:2093-109.

14. Breiman L. Bagging predictors. Machine Learning. 1996;24:123-40.

15. Rubin DB. Multiple Imputation for Non-Response in Surveys. New York: Wiley; 1987.

16. Farkouh ME, Domanski M, Sleeper LA, Siami FS, Dangas G, Mack M, et al Strategies for multivessel revascularization in patients with diabetes. $N$ Engl $J$ Med. 2012;367:2375-84.

17. Grundy SM. Pre-diabetes, metabolic syndrome, and cardiovascular risk. J Am Coll Cardiol. 2012;59:635-43.

18. Wilson PW, D'Agostino RB, Parise H, Sullivan L, Meigs JB. Metabolic syndrome as a precursor of cardiovascular disease and type 2 diabetes mellitus. Circulation. 2005;112:3066-72.

19. Ogden CL, Carroll MD, Kit BK, Flegal KM. Prevalence of obesity in the United States, 2009-2010. NCHS Data Brief No. 82, January 2012. Available at: http:// www.cdc.gov/nchs/data/databriefs/db82.pdf.

20. Wang YC, McPherson K, Marsh T, Gortmaker SL, Brown M. Health and economic burden of the projected obesity trends in the USA and the UK. Lancet. 2011;378:815-25.

21. Thourani VH, Weintraub WS, Stein B, Gebhart SS, Craver JM, Jones EL, et al Influence of diabetes mellitus on early and late outcome after coronary artery bypass grafting. Ann Thorac Surg. 1999;67:1045-52. 
22. Barzilay JI, Kronmal RA, Bittner V, Eaker E, Evans C, Foster ED. Coronary artery disease and coronary artery bypass grafting in diabetic patients aged $>$ or $=65$ years (report from the Coronary Artery Surgery Study [CASS] Registry) Am J Cardiol. 1994;74:334-9.

23. Mack MJ, Banning AP, Serruys PW, Morice MC, Taeymans Y, Van Nooten G, et al. Bypass versus drug-eluting stents at three years in SYNTAX patients with diabetes mellitus or metabolic syndrome. Ann Thorac Surg. 2011;92: 2140-6.

24. Stewart RD, Lahey SJ, Levitsky S, Sanchez C, Campos CT. Clinical and economic impact of diabetes following coronary artery bypass. J Surg Res. 1998;76:124-30.

25. Smith LR, Milano CA, Molter BS, Elbeery JR, Sabiston DC Jr, Smith PK Preoperative determinants of postoperative costs associated with coronary artery bypass graft surgery. Circulation. 1994;90:II124-8.

26. Zhang H, Yuan X, Osnabrugge RL, Meng D, Gao H, Zhang S, et al. Influence of diabetes mellitus on long-term clinical and economic outcomes after coronary artery bypass grafting. Ann Thorac Surg. 2014;97:2073-9.

27. Hlatky MA, Boothroyd DB, Baker L, Kazi DS, Solomon MD, Chang TI, et al. Comparative effectiveness of multivessel coronary bypass surgery and multivessel percutaneous coronary intervention: a cohort study. Ann Intern Med. 2013;158:727-34

28. Raza S, Sabik JF, Masabni K, Ainkaran P, Lytle BW, Blackstone EH. Surgical revascularization techniques that minimize surgical risk and maximize late survival after coronary artery bypass grafting in diabetics. $J$ Thorac Cardiovasc Surg. 2014;148:1257-66.e9.

29. Knowler WC, Barrett-Connor E, Fowler SE, Hamman RF, Lachin JM, Walker EA, et al. Reduction in the incidence of type 2 diabetes with lifestyle intervention or metformin. N Engl J Med. 2002;346:393-403.

30. Tuomilehto J, Lindstrom J, Eriksson JG, Valle TT, Hamalainen H, IlanneParikka $\mathrm{P}$, et al. Prevention of type 2 diabetes mellitus by changes in lifestyle among subjects with impaired glucose tolerance. $N$ Engl $J$ Med. 2001;344:1343-50.

31. Herman WH, Hoerger TJ, Brandle M, Hicks K, Sorensen S, Zhang P, et al. The cost-effectiveness of lifestyle modification or metformin in preventing type 2 diabetes in adults with impaired glucose tolerance. Ann Intern Med. 2005;142: 323-32.

32. Huang ES, Meigs JB, Singer DE. The effect of interventions to prevent cardiovascular disease in patients with type 2 diabetes mellitus. Am J Med. 2001;111:633-42.

33. Mannucci E, Dicembrini I, Lauria A, Pozzilli P. Is glucose control important for prevention of cardiovascular disease in diabetes? Diabetes Care. 2013;36(Suppl 2):S259-63.

Key Words: Coronary artery bypass grafting, diabetes, health care costs

Readers who found these articles interesting may also like to read the following papers found in recent and future issues of our sister publications, Seminars in Thoracic and Cardiovascular Surgery and Operative Techniques in Thoracic and Cardiovascular Surgery!

\section{Acquired Cardiovascular Disease: Coronary Artery Disease}

News and Views: Stephen Fremes. Outcomes of Arterial Revascularization. Semin Thorac Cardiovasc Surg. Autumn 2014;26(3): 174-175.

News and Views: Brian Buxton. Editorial on Multiple Arterial Grafting. Semin Thorac Cardiovasc Surg. Autumn 2014;26(3): 176-178.

News and Views: A. P. Kappetein. Role of PCI in the Treatment of Left Main Coronary Disease. Semin Thorac Cardiovasc Surg. Autumn 2014;26(3):187-191.

State of the Art: Victor Ferraris. Use of Anti-platelet Drugs after Cardiac Operations. Semin Thorac Cardiovasc Surg. Autumn 2014;26(3):223-230.

John Conte. Repair of Postinfarct Ventricular Septal Defect: Anterior Apical Ventricular Septal Defect. Oper Tech Thorac Cardiovasc Surg. Spring 2014;19(1):96-114.

Thomas Gleason. Repair of Postinfarction Ventricular Septal Defect: Posterior Inferior Ventricular Septal Defect. Oper Tech Thorac Cardiovasc Surg. Spring 2014;19(1):115-126. 


\section{APPENDIX E1. VARIABLES CONSIDERED IN ANALYSES \\ Demographics}

Age $(\mathrm{y})^{*}$, sex $^{*}$, race*, weight $(\mathrm{kg})$, height $(\mathrm{cm})$, weight/height ratio, body surface area $\left(\mathrm{m}^{2}\right)$, body mass index $\left(\mathrm{kg} \cdot \mathrm{m}^{-2}\right)^{*}$

\section{Symptoms and Surgical Priorities}

New York Heart Association functional class (I-IV),* emergency surgery

\section{Cardiac Comorbidity}

Prior myocardial infarction, * atrial fibrillation or flutter,* complete heart block or pacer,* heart failure, ${ }^{*}$ ventricular arrhythmia, left ventricular dysfunction (none, mild, mild to moderate, moderate, moderate to severe, severe)*

\section{Noncardiac Comorbidity}

Peripheral arterial disease,* carotid disease, ${ }^{*}$ hypertension,* chronic obstructive pulmonary disease, ${ }^{*}$ history of smoking, ${ }^{*}$ prior stroke, $*$ bilirubin $\left(\mathrm{mg} \cdot \mathrm{dL}^{-1}\right), *$ total cholesterol $\left(\mathrm{mg} \cdot \mathrm{dL}^{-1}\right){ }^{*} \quad$ high-density lipoprotein $\left(\mathrm{mg} \cdot \mathrm{dL}^{-1}\right),{ }^{*}$ low-density lipoprotein $\left(\mathrm{mg} \cdot \mathrm{dL}^{-1}\right)$, triglycerides $\left(\mathrm{mg} \cdot \mathrm{dL}^{-1}\right)$, ${ }^{*}$ creatinine $\left(\mathrm{mg} \cdot \mathrm{dL}^{-1}\right), *$ blood urea nitrogen $\left(\mathrm{mg} \cdot \mathrm{dL}^{-1}\right),{ }^{*}$ hematocrit $(\%)^{*}$

\section{Coronary Anatomy}

Number of systems diseased ( $\geq 50 \%$ stenosis), $*$ left main trunk (LMT) disease, any LMT disease, LMT disease ( $\geq 70 \%$ stenosis), ${ }^{*}$ LMT disease $(\geq 50 \%$ stenosis $), *$ left anterior descending coronary artery (LAD) system disease, any LAD system disease, LAD system disease $(\geq 70 \%$ stenosis), ${ }^{*}$ LAD system disease ( $\geq 50 \%$ stenosis), ${ }^{*}$ left circumflex (LCx) coronary artery system disease, any LCx system disease, LCx system disease $(\geq 70 \%$ stenosis), ${ }^{*}$ LCx system disease $\left(\geq 50 \%\right.$ stenosis), ${ }^{*}$ right coronary artery (RCA) system disease, any RCA system disease, RCA system disease ( $\geq 70 \%$ stenosis), ${ }^{*}$ RCA system disease $(\geq 50 \% \text { stenosis })^{*}$

\section{Experience}

Date of operation (years since January 1, 1972)* 


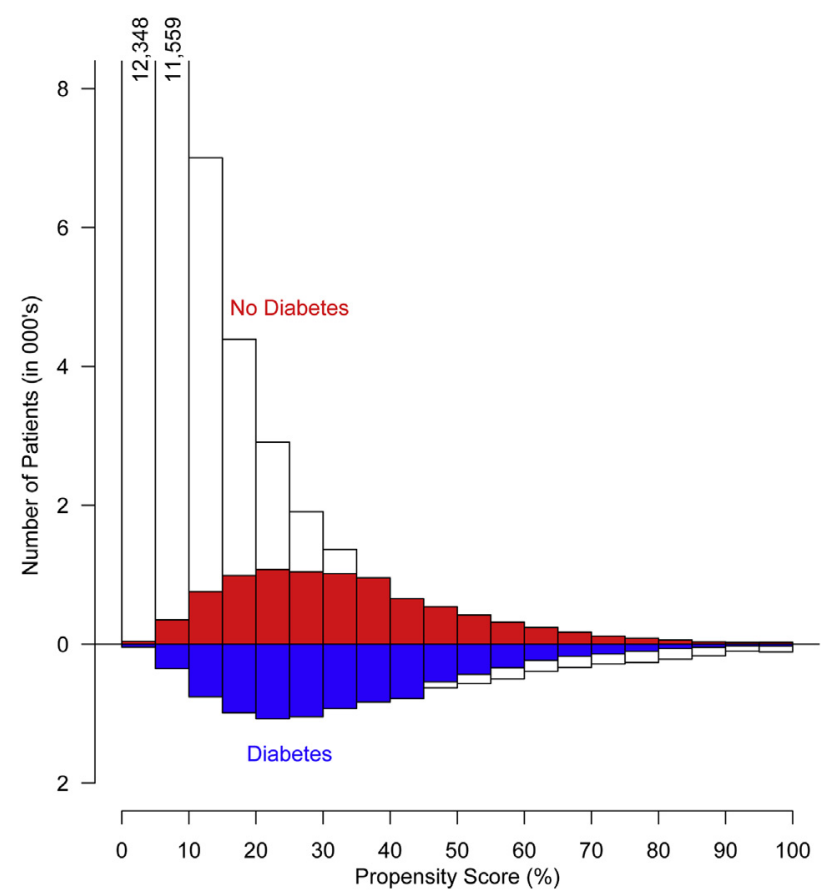

FIGURE E1. Mirrored histogram of distribution of propensity scores for diabetes and no diabetes (shaded area represents matched patient cohorts).

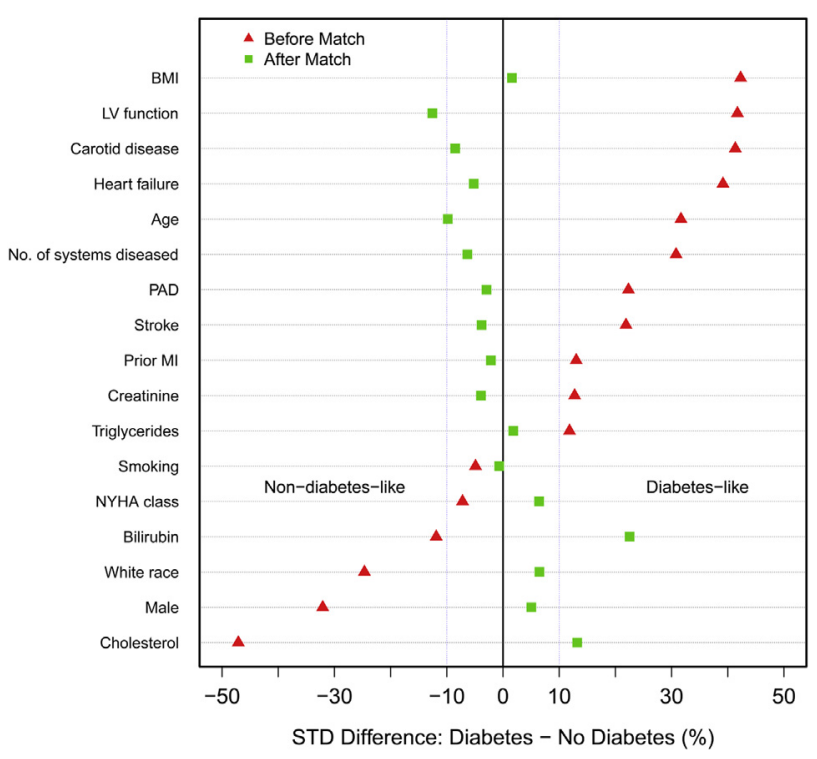

FIGURE E2. Covariable balance plot before and after propensity-score matching on selected covariables (Austin PC, Mamdani MM. A comparison of propensity score methods: a case study estimating the effectiveness of post-AMI statin use. Stat Med. 2006;25:2084-106.) Diabetes-like characteristics are on the right; non-diabetes-like characteristics are on the left. $B M I$, Body mass index; $L V$, left ventricular; $P A D$, peripheral arterial disease; $M I$, myocardial infarction; $N Y H A$, New York Heart Association; STD, standardized.
TABLE E1. Factors associated with diabetes among patients undergoing coronary artery bypass grafting (parsimonious model)

\begin{tabular}{|c|c|c|c|}
\hline Factor & Estimate $\pm \mathrm{SE}$ & $\begin{array}{c}P \\
\text { value }\end{array}$ & $\begin{array}{c}\text { Reliability } \\
(\%)\end{array}$ \\
\hline \multicolumn{4}{|l|}{ More common in diabetics } \\
\hline Higher body mass index* & $2.09 \pm 0.13$ & $<.0001$ & 100 \\
\hline NYHA functional class IV & $0.063 \pm 0.029$ & .03 & 67 \\
\hline \multicolumn{4}{|l|}{ Cardiac comorbidities } \\
\hline Heart failure & $0.37 \pm 0.045$ & $<.0001$ & 99 \\
\hline More systems diseased $\dagger$ & $0.30 \pm 0.027$ & $<.0001$ & 100 \\
\hline LCx system disease $\ddagger$ & $0.20 \pm 0.038$ & $<.0001$ & 100 \\
\hline $\begin{array}{l}\text { Worse left ventricular } \\
\text { function }\end{array}$ & $0.15 \pm 0.011$ & $<.0001$ & 96 \\
\hline \multicolumn{4}{|l|}{ Noncardiac cormorbidities } \\
\hline Peripheral arterial disease & $0.40 \pm 0.039$ & $<.0001$ & 100 \\
\hline Carotid disease & $0.16 \pm 0.040$ & $<.0001$ & 68 \\
\hline Hypertension & $0.30 \pm 0.036$ & $<.0001$ & 90 \\
\hline Stroke & $0.25 \pm 0.054$ & $<.0001$ & 88 \\
\hline Higher triglycerides $\S$ & $0.10 \pm 0.0036$ & $<.0001$ & 97 \\
\hline Lower bilirubin $\|$ & $0.49 \pm 0.014$ & $<.0001$ & 75 \\
\hline \multicolumn{4}{|l|}{ More common in nondiabetics } \\
\hline Black or other race $\llbracket$ & $0.50 \pm 0.041$ & $<.0001$ & 97 \\
\hline LMT system disease $\ddagger$ & $-0.20 \pm 0.055$ & .0009 & 100 \\
\hline Smoking & $-0.37 \pm 0.026$ & $<.0001$ & 96 \\
\hline Lower cholesterol $^{\#}$ & $-1.20 \pm 0.07$ & $<.0001$ & 97 \\
\hline Lower hematocrit $* *$ & $-1.29 \pm 0.057$ & $<.0001$ & 87 \\
\hline Intercept & $-2.28 \pm 0.56$ & .001 & \\
\hline
\end{tabular}

C-statistic $=.83$. The reliability indicates percentage of times the factor appeared in 500 bootstrap models. SE, Standard error; NYHA, New York Heart Association; $L C x$, left circumflex coronary artery; $L M T$, left main trunk. * $\log$ (body mass index), logarithmic transformation. $\dagger \geq 50 \%$ stenosis. $\ddagger \geq 70 \%$ stenosis. $\S$ (Triglycerides/ $180)^{2}$, squared transformation. $\|(1 /$ bilirubin $)$, inverse transformation. $\llbracket$ Black or other race compared with white race. ${ }^{\#} \log ($ cholesterol), logarithmic transformation). $* *(\text { Hematocrit } / 40)^{2}$, squared transformation. 